\title{
Lifelong Learning in Japan: Policy, Concepts, and the Present Situation
}

\author{
Mitsuru Takahashi \\ Graduate School of Education \\ Tohoku University, Sendai, Japan \\ taka-man@sed.tohoku.ac.jp
}

\begin{abstract}
In this article, I'll review the processes of the system of social education in post-war Japan, while going over its organizing principles. Next, it summarizes the development of Japan's lifelong learning policy since the 1960s. In particular, it reviews the types of reforms that have been advanced amid the economic globalization since the 1990s. Lastly, I summarize the current state of the relationship between governance reform for social education facilities such as Kominkan-a central issue in lifelong learning policy recently-and community development policy, by presenting several arguments about how this should be evaluated.
\end{abstract}

Keywords- Lifelong Learning Policy; Liberal Reform; Community Development; Outsourcing of Kominkan

\section{INTRODUCTION}

In its mission toward modernization, Japan's educational policy has been greatly influenced by the systems and theories of Western countries since the Meiji period; however, it has achieved its own form of development that is focused on unique national issues. While the social education policy following Japan's 1945 defeat in World War II was also institutionalized based on Western principles of liberalism as well as the strong influence of the UNESCO's lifelong education policy in the 1960 s, we can essentially say that Japan's social education policy has advanced to become the educational policy of a nation-state.

A lifelong learning policy is like the faces of Janus. In other words, people have noted that these policies possess a twosided quality to them [1], [2]. [3] promotes lifelong learning policy with the goals of human development, improving the quality of life for all, and advancing democracy, whereas the OECD perceives it from the human capital theory, positioning lifelong learning policy as a means for competition in a global society [4]. This paper analyses the effects from this international policy expansion, and the path of which the Japanese lifelong learning policy has taken amid the globalization process of the 1990s onwards.

In the following, the paper first reviews the processes of the system of social education in post-war Japan, while going over its organizing principles. Next, it summarizes the development of Japan's lifelong learning policy since the 1960s. In particular, it reviews the types of reforms that have been advanced amid the economic globalization since the 1990s. Lastly, this paper summarizes the current state of the relationship between governance reform for social education facilities such as public halls - a central issue in lifelong learning policy recently - and community planning policy, by presenting several arguments about how this should be evaluated.

\section{DISCUSSION}

\section{A. Liberal Reforms And Lifelong Learning Policy-Shifting Toward Learning}

\section{1) The Era of Liberal Reforms}

In the 1980s, there was a major shift in the Japanese stance of state welfare intervention. That is, the policy was changed toward neoliberalism. The Ad Hoc Council on Education, established under the then-prime minister Yasuhiro Nakasone, was instrumental in the shift. Unlike the "permanent" body of the Central Council for Education, the term "ad hoc" used here does not refer to something being temporarily established; rather, it is used to mean "impromptu," that is, "established at a turning point." It clearly indicated that Japan was at a major turning point for the era, and it was attempting to shift the principles of educational organization.

During Japan's transition to an era of liberal reform, the concept of lifelong education was replaced with that of lifelong learning. Since then, the privatization and marketization of education have been progressing in a variety of forms. For social education facilities, the marketization of facilities that are established and managed by the public was promoted. For instance, the designated administrator system created opportunities for private enterprises, such as community organizations, non-profit organizations (NPOs), and companies to participate. An educational market was formed, and various agents were able to enter as equal supporters.

[5], [6] The impact of this liberalization has not only shifted the principles of marketization, but also changed the fundamental framework with which we perceive lifelong learning. With the marketization of learning, learning has now transformed into a relationship between consumers and sellers, or consumers and suppliers, instead of a mutual relationship between learners. In other words, when market principles are introduced, a price is ascribed to the "value of learning," and access to it depends on the ability to pay.

The key point is that the aim of this was to redefine the relationship between the state and individuals. In other words, the goal of educational policy was not to attempt to achieve 
equality between individuals as a duty of the state, but to increase employability through personal responsibility, thus emerging to the top in the competition with other nations. In part, globalization increases nationalism, thus blending strangely with liberalism. The state's role in all this is no longer to guarantee a safety net but, at most, to prepare a "trampoline" (i.e., opportunities for lifelong learning) for citizens to change jobs safely [7].

Still, since the 1990s, people have started raising new issues from a national perspective, touting the once-dismantled public nature of social education. The issues that require governance are the four pillars of lifelong learning, which include education related to modern issues such as recurrent education, volunteer activities, human rights education, and environmental education, and issues such as extracurricular activities for children. Additionally, problematic behavior in children is starting to be treated as a social issue; as a result, there is a demand for nature-based experience programs and real-world experience programs to be offered. Further, debates on compelling social service activities are on an upsurge.

The methods of enterprises providing governance are criticized as "inefficient" and "one size fits all"; hence,the trend toward demanding an agency that is accountable for welfare services locally. Parallel to this, the role of the community is being stressed even in the realm of social education, and people are paying attention to "community development through learning" with the aim of rebuilding the public nature of social education.

2) An Era of Learning-The Politics of "Education" and "Learning"

This section examines two concepts developed from the idea of lifelong learning based on liberalism. To start with, first is the shift from the concept of "education" to the one of "learning." In the 1960s, when UNESCO debates were introduced in Japan, the word "lifelong education" was used. Guaranteeing people with opportunities to learn as a right throughout their lives became a subject for policymakers to deal with. Still, although Japan tried to expand educational opportunities through its policies, it could be said that there was an extremely weak awareness of the issue pertaining to eliminating social disparities and inequality in educational opportunity.

However, since the mid-1980s, the concept of "lifelong learning" has become popular, even internationally. To be more precise, a shift in word usage from "education" to "learning" could be seen in policy debates. In the case of Japanese policy, it was explained that the concept of "education" was from the perspective of providing learning opportunities, while "learning" was from the perspective of learners. In other words, it was nothing more than a difference in points of view. Furthermore, a society of lifelong learning had to be learner-driven. As such, professionals were seen as educational facilitators rather than educators. The concept of "education" has become unpopular or even - to exaggerate slightly_detested.

This explanation of changing perspectives is nothing more than a superficial one. Several factors, in the following, could explain such a conceptual shift.
The first is a shift in theories about learning. Constructivism is very influential in the social sciences. Conventional, traditional learning theory is about imparting knowledge on passive students through instructor-led education, whereas constructivism proposes an epistemological turn in that theory. It asserts that learners are always active and that they should be perceived as agents that construct knowledge and meaning through "dialogue" and "experience." From that perspective, "learning" rather than "education" is the appropriate term [8], [9].

Second, learners are perceived as agents that select learning opportunities themselves. Since the 1980s, Japan has advanced policies that attempt to commercialize state welfare services such as social security, social welfare, and education as it "dismantles" the welfare state. This progresses not only through policy, but also through the deep penetration of individualization and personalization of learning; these must also be seen as the foundation of the mentioned marketization. In the lifelong learning market, there is an image of learnerconsumers selecting a variety of pre-existing products from a variety of learning opportunities (markets) "based on their own interests." The claim has been made that this itself is a learnercentered philosophy and a shift toward learner autonomy. Thus, that constitutes the presentation of the image of autonomous learners.

However, there is another "desperate side" hidden in these optimistic learners. Lifelong learning policy is a means to achieve economic growth and competition, linked to the knowledge-based society theory. Amid the intense global economic competition, continuing to learn throughout one's life is beginning to be seen as a "duty." The "internalization" of lifelong learning is being sought. In this way, education is transforming from a "treasure within" to a "pressure within." Disparities actually drive competition. From the policy perspective, the Japanese government has created and enforced its slogan, "To the victor go the spoils, and to the defeated go opportunities to try again." Learning is positioned as the opportunity to try again.

To summarize from the perspective of shifting state intervention, this can be interpreted as a shift from protective policies using redistribution toward social-order policies that drive competitive attitudes. Put simply, these policies are set up so that education no longer uses national funds, but everyone is expected to learn actively and, as a result, to possess the will to emerge victorious from competitions with others.

\section{3) An Era of Evaluation-Evidence-Based Educational}

\section{Practice}

Furthermore, one highly influential viewpoint in the era of lifelong learning is the idea of evidence-based practice. Specifically, educational discourse demands that educational policy and educational practice should be based on scientific evidence of quantification.

At first glance, that does not seem problematic. Educational practice is a field that constantly shakes one's faith, and it should be understood that there is demand for hard evidence to support practice. Indeed, there is no need to contradict immediately the idea of evidence-based practice. However, it is important to understand accurately the limits of this discourse. 
There are three criticisms of this viewpoint [10], [11]:

The first is that, under the philosophy of evidence-based educational policy and practice, diverse educational goals are simplified to a single measurable indicator: improvement of academic ability. Then, the only remaining question examines which type of interventions is most "effective" at achieving this. However, although we should be aware of the fact that there are indicators that can and cannot be quantified, we deliberately disregard the quantifiable limitation at times. As a result, we risk falling into the trap of restricting goals to only those that can be quantified.

The second is that this way of thinking describes the actions of educators using technician models. Yet, is it truly appropriate to describe the work of educating with that sort of technician model? First, education is practiced in a great variety of places, and the conditions are fluid. Educators must make decisions suitable to the current circumstances of a learner through "reflection in practice" and "reflection on practice" to influence the learner. Experiential knowledge, practical knowledge, and a rich practical repertoire gained through experience are essential in educational practice. Educators are not technicians; they are reflective practitioners and artists.

Third - and this is the most important point - this discourse excludes debate over what the meaning of educational practice is or what the goals of education are. It falls into the trap of taking the goals of education as a given and limiting investigation to what methods are most effective and efficient for reaching those goals. However, what is important in educational practice is the issue of the value of practice, and we must have in-depth debates about what should be achieved through educational practice. As pointed out by UNESCO's Delors Report [3], we must constantly question what kind of society is a "good society" and based on that, recreate the goals and content of a "good education."

The act of educating is not a mere technical process, but a practice about which the value of these acts involved should be questioned constantly and rigorously. Moreover, it has a speculative nature, creating the society of the future through the education-driven social growth of individuals. When focus is limited to efficiently achieving educational practice that assumes a given goal, it maintains the current governing and social structures, leading only to the development of orthodoxy. As a result, what we need most from educationthat is, the opportunity to create something new-vanishes.

\section{B. Recent development Of Lifelong Learning Policy-The Mainstreaming Of Community}

\section{1) Liberal Reforms and Governance Reforms}

There are three forms of privatization of social services: marketization, community outsourcing, and individualizations. From the mid-1980s, when lifelong learning policy was in full swing, these policies commercialized learning by nature, and they were designed to nurture the leisure industry and the education and culture business. Although the design itself did face setbacks because of the collapse of the so-called bubble, the foundation for commercialization was laid by moving toward charging fees for lectures and opening up the responsibility for social education to for-profit companies.

However, on-going privatization of administrative operations is a different way in which governance of social education has transformed. In the area of social education governance, first, in the 1970s, the government took the measure of turning Kominkans into community centers as part of community policy and outsourcing the administrative operations to local organizations. Meanwhile, a method used primarily for ordinance-designated cities is to outsource management to facilities that use foundations funded by local governments. Under pressure for administrative and fiscal reform, the practice of taking facilities from the direct management of the Board of Education and outsourcing them to foundations were widespread all over the country.

Heading into the 1990s, there was a shift toward a new form of governance. Now, the "designated administrator system" in question marks a new stage in which the previous privatization process went a step further. To be specific, in traditional outsourcing and management outsourcing systems, management can only be outsourced to companies financed by local public bodies. For such outsourcing, work is outsourced based only on private-law contracts, and administrative authority rests with the local public bodies. However, in the designated administrator system, designated administrators selected to handle governance are accorded administrative authority over facilities. Furthermore, designated administrators include not only foundations, but also private enterprises, NPOs, and community organizations; therefore, under this system, they are able to set usage fees themselves (although they do need the approval of the local government) in order to turn a profit.

This goes beyond commercializing services and using private-sector methods. In the past, it was assumed that the administration would set up and run facilities, but as government and governance are separated, systems are set up so that administrative authority is entrusted to the private sector, companies included. As a result, the private outsourcing of social education facilities, such as Kominkans, continues to advance in the form of outsourcing locally and to foundations. Another outcome is that learning facilities, such as Kominkans, are considering and attempting to implement fees based on the view that beneficiaries of a service should pay for it.

These governance reforms are being advanced as part of the creation of systems in which Kominkans contribute to "community development" based on the participation of residents. Here, the move toward charging fees is not uniformly about charging fees per se; it is a trend of distinguishing learning opportunities "with a public nature" that address community development and modern issues from ventures "with a private nature" such as hobbies and educational ventures, then charging fees for those that provide private education. Accordingly, although it may seem unrelated at first glance, despite the merging of the public nature of social education with community development, it is becoming clear that privatization is progressing in two forms: privatesector outsourcing and the move toward fee charging. 


\section{2) The Progression of Local Outsourcing for Kominkans}

Although it has been pointed out since the 1990s that the private-sector outsourcing of social education facilities is progressing, this progress also takes a variety of forms when classified. Outsourcing is most advanced when it comes to social education facilities such as Kominkans. As you will see, the rate of outsourcing had exceeded $20 \%$ by early 2000 s. Moreover, the outsourcing of facilities, such as museums and libraries, was advancing. Both these types of facilities were characterized by the increasing entry of private enterprises.

What about Kominkans? Until the 2000s, Kominkans had essentially been publicly established and publicly managed. However, outsourcing is increasingly becoming more common, and one advantage of the present stage is that it takes the form of local outsourcing, meaning that resident-administered organizations, such as participation in community organizations, are increasingly preparing to take over operations.

How is this local outsourcing set up? Up until now, social education facilities, such as Kominkans, were not only established by the government, but they were also staffed by government employees appointed by the Board of Education, even if there was a part-time director that was elected locally. However, these employees had primarily taken the responsibility for planning and executing Kominkan businesses. Residents in a Kominkan's district had taken on the role of participating in Kominkan operations and providing assistance. However, although administrative operating expenses are subsidized with public funds under the outsourcing system, the system is set up so that local recipient organizations employ workers such as directors and Kominkan staffs, and these staffs and the steering committee are responsible for planning and executing Kominkan businesses. The role of the administration is to supervise from the position of an outsourcer, verifying that operations and expenditure budgets are being carried out appropriately.

Consequently, it is expected that, in this designated administrator system, the administration will entrust all operations management work to selected vendors before evaluating the results. The role of the administration is that of an evaluator, and there is a shift toward a relationship in which the administration exercises its authority as a manager. This understanding achieved through quantification of business results and evaluation by the administration is based on standards of "efficiency." This system restructures the operations management of Kominkans and carries the risk of rearranging the relationship between government and citizens into a vertical power relationship. We will return to this subject later.

\section{3) Community Development and Social Education}

When it comes to this governance reform, one aspect that we need to be watchful - and an important point for Japanese social education in recent years - is the demand for social education to contribute to community development. For instance, one issue that has been raised is the attempt to restructure social education governance by connecting learning activities to community development. To be more specific, through diverse learning activities, such as learning about recent and social issues, the policy aims to raise consciousness regarding the independence of local citizens, to give every local resident a sense of ownership, and to allow people to acquire the knowledge and skills they need to behave proactively (self-reliance). At the same time, it works to link the results of learning activities with the implementation of community development through working together (mutual aid and cooperation). Because of this, social education facilities, such as Kominkans, assume a central role. For example, efforts to form local communities with "places of learning" at their core are moving forward with support and dissemination of initiatives to connect learning activities with solving local issues.

Exactly what kind progress is being made in community development? Let us take a look at the example of Tome city in Miyagi prefecture. Tome is a municipality with a population of 82,000 located in an agricultural region in northern Miyagi prefecture. There are 22 elementary schools, 10 middle schools, and 17 Kominkans. The Kominkans were originally publicly established and publicly operated; however, since 2013, the "community steering councils" that primarily comprised locally run organizations called residents' associations have been formed, and these councils have taken on the management and operation of the Kominkans. Administrative operating expenses depend on public funding, but those local organizations hire one director and two to three Kominkan employees. The business conducted by Kominkans is generally planned and executed individually by each Kominkan.

In Tome City, since 2015, there has been progress in the business of formulating plans for community development using these Kominkans as a base. Let us look at an example from a certain Kominkan. In order to formulate a community development plan, a planning committee of 15 people as well as a planning task force of 54 people from 38 neighborhood associations and 10 groups collaborated, and they formulated a community development plan for their district, after about a year of investigation and discussion.

The planning committee comprised four task forces. They were the Health and Welfare Task Force, the Industry and Tourism Task Force, the Culture and Education Task Force, and the Environment and Disaster Prevention Task Force. First, one distinctive feature of this planning committee was the fact that it took up a comprehensive range of local issues-from economy and welfare to environment, disaster prevention, and education. Second, during the formulation process, people from a variety of local areas participated, and each task force formulated a plan based on dynamic discussions. To be specific, the task forces, in workshops, reviewed the strengths and appeal of the area as well as clarifying local issues. Based on this, the participants shared a common vision of the district's future and devised plans for systems and behaviors that would achieve that vision. In this way and following plan formulation process, residents with diverse backgrounds worked together to formulate a plan of action for the next 10 years and moved into the implementation stage.

Through this process, a community-development plan that is unique to the area was formed in the district with jurisdiction 
over all 17 Kominkans in the city. How should such community-development processes be evaluated from the perspective of social education? That should be discussed in relation to governance reform.

\section{CONCLUSIONS}

The institutionalization of social education in Japan has been advanced as state welfare policy. In areas with the social education committee system and system of public hall operations councils where the participation of residents is institutionally guaranteed, the establishment of facilities such as public halls and lifelong learning centers and the placement of specialized employees have achieved a high standard, even on an international scale. Although a rich practice was built up as this history developed, it became mired in the dilemmas of bureaucratization and institutionalization. In the field of public social education, the institutionalization process is seen as a process that forgoes active participation of citizens in the operations and decision-making processes for education. On top of the diversification and heightening of the learning needs of citizens and the arrival of a risk society, the sense of individualization and uncertainty of life is also increasing. Amid all this, there is a growing inability to cope with these factors, thus resulting in the increasing lack of interest in social education. The justification for the existence of the bureaucratic structures is being questioned.

While the local outsourcing system has the potential to be reformed by citizens taking over administrative operations, there is also the risk that the relationship between the government and citizens would be changed completely. As discussed earlier, in the designated administrator system, understanding is being achieved through quantification of business results, and evaluation by the administration is being carried out, but there remains a strong demand for the standard to be on "efficiency." As citizens implement policies and the government exercises influence as the evaluator, there are concerns that efficiency will be prioritized over educational goals such as creating a social value and achieving democracy.

The principle in opposition to this is actually participation in the decision-making process, namely, the principle of democracy. To be specific, the important thing is to create a governance body in which citizens are substantively involved in a series of processes including planning, decision-making, implementation, and evaluation; the final authority for decisions should belong to these organizations of governance rather than the government. In other words, decentralization should be understood as a progression of the delegation of authority to citizens within municipalities, rather than a process that occurs within the government. In particular, there is a demand for facilities, such as public halls and libraries established on the regional level to be considered units of governance, and for a creation of collaboration incorporating the government, citizens, organizations, and companies. Accordingly, this can be referred to as community governance. Community development based on such governance would likely yield significant results.

Furthermore, first, it is important to evaluate the current administrative operations based on citizen participation and, if there is an issue, discuss the direction of a solution. The designated administrator system is nothing more than one option for a solution. Second, the complete delegation of operations management leads to a rejection of the role of the government. Important points to be discussed are clarifying the government's proper role (obviously including financial security), establishing the systems necessary for the government's primary work, and determining how to position the specialized nature of social education professionals in that context.

After all, the only thing that can oppose the intensifying market liberalization occurring in public social education on the back of globalization is democracy and citizen participation in planning with a local foundation. Nevertheless, this cannot be accomplished with "small democracy" alone. It must be bolstered by financial support from the state and the establishment of legal rules. What social education needs is a new governance regime [12].

\section{REFERENCES}

[1] Elfert, Maren, UNESCO, the Faoure Report, the Delors Report, and the Political Utopia of Lifelong Learning, European Journal of Education, Vol. 50, No. 1, 2015, pp88-100.

[2] Rubenson, Kjell, Lifelong Learning for All: Challenges and Limitations of Public Policy, University of British Columbia, 2001, pp242-248.

[3] Unessco, Learning: The Treasure Within; Report to UNESCO of the International Commision on Education for the Twenty-first Century, Unesco Publishing, 1996

[4] OECD, The Knowledge-Based Economy, Paris, 1996.

[5] TAKAHASHI Mitsuru, Modern Practice of Social Education,Sofushya, 2003.

[6] TAKAHASHI Mitsuru, Roform of German Welfare State and Adult Continuing Education, Sofushya, 2003.

[7] Milles, Vince, Employability, globalisation and lifelong learning: a Scottish perspective, International Journal of Lifelong Education, Vol.21, Issue 4, 2002, pp347-356.

[8] TAKAHASHI Mitsuru, NPO and Governance of Lifelong Learning, Toshindo,2009.

[9] TAKAHASHI Mitsuru and MAKIISHI Takiko, Learning Space and Human Support Professional, Sofoshya, 2015

[10] Biesta, G.J., Beyond Learning : Democratic Education for Human Future, Paradigm Publishers, 2006

[11] Biesta, G.J., Good Education in an Age of Measurement: Ethics, Politics, Democracy, Paradigm Publishers, 2010.

[12] Dare, Roger, Specifying Globalization Effects on National Policy: a Focus on the Mechanisms, Journal of Education Policy, Vol. 14, No.1, 1999, pp1-17 